\title{
Carbon Disclosure Practices in Turkey: A Study on ISE Listed Companies
}

\author{
N.Nalan Altintas ${ }^{1}$

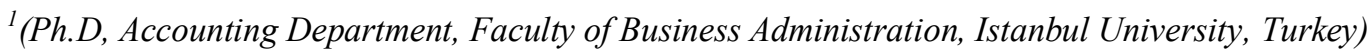

\begin{abstract}
The purpose of this study is to determine the climate change and carbon disclosure practices of Turkish listed companies for the 3-year period before the ratification of Kyoto Protocol in 2009. This study evaluates the climate change and carbon emission information disclosed by companies in Istanbul Stock Exchange (ISE)-100 Index. The study is based on disclosures made in the annual reports of 27 companies across ten carbon intensive sectors (iron and steel, energy, cement, oil and gas, pulp and paper, chemicals, glass, compost, dye, airline) covering the period of 2006-2008. Content analysis is used to measure the changing levels of information provision. The results indicate that companies in carbon intensive sectors in ISE100 Index for the period mentioned above were disclosing limited carbon emission information, and the relative volume of such information in annual reports were increasing from 2006 to 2008, but not at an expected level. Moreover, these companies revealed almost no information related to climate change.
\end{abstract}

Keywords: Climate change, GHG emmission, Carbon disclosure, Emission abatement, ISE-100 Index

\section{Introduction}

Fast paced industrialization has significant impact on various environmental issues. One of these is the increase of the emissions of GreenHouse Gases (GHG). As a result of this, global warming started to come on the scene. The most important results of global warming are melting of glaciers and rise of sea level, increase of the average temperature of the world, and deformation of ecological stability.

Climate change is regarded by many as the most significant social and environmental challenge the Earth currently faces. In recent years carbon dioxide has received much attention because its concentration in the atmosphere has risen to approximately $30 \%$ above natural background levels and will continue to rise into the near future. Scientists have shown that this increase is a result of human activities that have occurred over the last 150 years, including the burning of fossil fuels and deforestation. Because Carbon dioxide is a GHG, this increase is believed to be causing a rise in global temperatures. This is the primary cause of climate change and is the main reason for increasing interest in the carbon cycle (NSF, 2011)

Reporting information about an organisation's social and environmental interactions has become a contemporary feature of $21^{\text {st }}$ Century business. This reporting has developed in a predominantly ad hoc manner and emerges from a variety of sources, but evidence suggests that it is an important and increasingly prevalent source of information supplementary to the organisation's financial reports. Corporate environmental reporting has become an important part of corporate reporting at large. Many companies have started to improve the disclosure of their strategies for mitigating their carbon footprint, managing carbon risk, and meeting their targets for GHG emissions.

The form of companies' reporting on their environmental performance varies widely-from brief statements in their annual reports to extensive, stand-alone environmental reports complete with photographs, graphs and other diagrammatic and pictorial representations of relevant information.

Environmental disclosures constitute part of what is generally termed social responsibility reporting. Social responsibility disclosures include, among other things, disclosures relating to the interaction between an organisation and its physical and social environment. Social responsibility reporting may include information about environment, energy, human resources and community involvement. This paper is concerned with disclosures related to the climate change and carbon emissions.

The remainder of the study is organized as follows: In part two, background for regulations related to climate change and GHG emissions and for the current situation in Turkey is provided. Literature review is given in the third section. The research design including sample selection, data collection and research methodology is discussed in part four. The findings are presented in part five, and the conclusion is contained in part six. 


\section{Major Regulations Related To Climate Change And Ghg Emissions And The Current Situation In Turkey}

\subsection{Major Regulations Related To Climate Change And GHG Emissions}

Two important international agreements address the pressing issue of reducing anthropogenic GHG emissions in the atmosphere: the United Nations Framework Convention on Climate Change (UNFCCC) and the Kyoto Protocol. The UNFCCC is a multilateral convention aimed at stabilising GHG concentrations in the atmosphere at a level that would prevent dangerous anthropogenic interference with the climate system. The Kyoto Protocol came into being on 11 December 1997 at the third Conference of the Parties (COP) to the UNFCCC, and entered into force on 16 February 2005. Details and rules about implementation of the Kyoto Protocol are contained in the Marrakesh Accords, which consist of decisions made by the COPs in its seventh session, held at Marrakesh, Morocco in 2001 (ACCA, 2010). Kyoto Protocol is the only international agreement which strives to prevent global warming and climate change. The purpose of the Protocol is to encourage the countries to reduce the emissions of carbon dioxide and the gases which cause GHG effect. The Kyoto protocol requires ratifying Annex I countries to reduce their emissions of a specified GHG basket by a collective average of 5\% below their 1990 levels (Bebbington and Larrinaga-Gonzalez, 2008).

The EU-15 took on a joint target under the Kyoto Protocol to reduce collective emissions of European Union countries by at least 8\% below 1990 levels in the Protocol's first commitment period (2008-2012). In June 2000, the EU launched its European Climate Change Programme (ECCP), which aimed to identify and develop all the necessary elements of an EU strategy to implement the Kyoto Protocol and achieve the EU-15 joint target. The centrepiece of the ECCP is the EU Emissions Trading Scheme (EU ETS) (ACCA, 2010).

Society's concern about the environment is reflected in the emergence of formal environmental performance standards such as the International Standards Organization's ISO 14001: Environmental Management Systems and Europe's Eco-Management and Audit Scheme (EMAS) (Porter et al., 2008).

\subsection{Current Situation In Turkey}

As a member of the OECD, Turkey was included among the Annex I and II countries when the UNFCCC was adopted in 1992. Under the convention, Annex I countries have to take steps to reduce emissions and Annex II countries have to take steps to provide financial and technical assistance to developing countries. However, in comparison to other countries included in these annexes, Turkey was at a relatively early stage of industrialization and had a lower level of economic development as well as a lower means to assist developing countries (Kaygusuz, 2009). In 2001 Turkey was removed from the list of Annex II countries, but remained on Annex I - with an accompanying footnote specifying that Turkey enjoys favourable conditions. Decision 26 of the 7th COPs removed Turkey from Annex II of the Convention and invited parties to the Convention to "recognize the special circumstances of Turkey, which place Turkey, after becoming a party, in a situation different from that of other parties included in Annex I to the Convention" (OECD, 2008). This led to an official acceptance of the UNFCCC by the Turkish Grand National Assembly in October 2003, followed by its enactment in May 2004 (Kaygusuz, 2009). Turkey ratified the Kyoto Protocol in May 2009 and the Protocol came into effect on August 2009. Signing the Kyoto Protocol does not put an additional burden on Turkey until 2012. Turkey as not being a party country on 1997 when the Kyoto Protocol have been signed, has no obligation of limiting and reducing emission in the coverage of Kyoto Protocol Annex-B (Kaya, 2008).

Besides these EU has many regulations about the matter. The EU Directive that implements the EU ETS requires that each participating country propose a National Allocation Plan (ACCA, 2010). Since Turkey is at the moment a EU Candidate Country, EU ETS is not applicable to the country (EEA, 2007). However, Turkey has submitted its First National Communication on February 2007 to the UNFCCC Secretariat. In addition, the National Climate Change Strategy (2010-2020) which was adopted by the decision of the Supreme Planning Council in May 3, 2010, will cover a period of 10 years. Based on the above mentioned Strategy Document, National Climate Change Action Plan (NCCAP) was completed in 2011 (MFA, 2011).

Turkey's national response to climate change is captured in its NCCAP, prepared to implement Turkey's National Climate Change Strategy, which was approved by the High Planning Council under the chairmanship of the Prime Minister on 3 May 2010. NCCAP is further guided by Turkey's Ninth Development Plan (2007-2013), relevant decisions of the COP and the COPs serving as the meeting of the Parties to the Kyoto Protocol, the United Nations Millennium Development Goals and relevant sectoral policies of the European Union (EU). The implementation of the NCCAP is coordinated by the Ministry of Environment and Urbanization (UN, 2013).

In addition The UNFCCC reporting guidelines on annual inventories require Parties included in Annex I to the Convention to provide annual national GHG inventories covering emissions and removals of direct GHGs (UNFCC, 2009). Turkey submitted the latest national GHG inventory in 2012 (UN, 2013).

No legislation corresponding to the EU legal basis on EMAS has been adopted yet. However, a law was passed in November 1999 paving the way for establishing a Turkish National Accreditation Body which is 
expected to play a role in EMAS implementation. A National Accreditation Body appointed in June 2000 (UNDP and EC, 2008). In addition, companies in Turkey can apply for ISO 14001 certification.

Regulation on Protection of Air Quality (Took effect upon publication in the Official Gazette Issue No.19269 of 02.11.1986), which is directly related to Air Pollution, has entered into force in order to put forth details of concrete application of the matter, for which a frame is formed under the Environment law. Objective of this Regulation is to control the smoke, dust, gas, steam and aerosol emissions that are discharged into the atmosphere as a result of any kind of activities, and to protect human and environment against any hazard that may arise from pollution of atmospheric environment. Furthermore, national regulations directly related to the air pollution caused by certain factors were issued. These regulations are as follows: Assessment and Management of Air Quality Regulation (2008), Regulation of Controlling Air Pollution Caused by Industry (2004), Regulation of Controlling Air Pollution Caused by Heating (2009), Regulation of Controlling Air Pollution Caused by Industrial Facilities (2004) (Aydın et al., 2010). As a matter of fact, there are some regulations related to GHG emission reductions; however, within Turkey there are no requirements, legislative or professional, for firms to disclose environmenal initiatives undertaken, or the costs (however measured) the firm has imposed on the environment.

The Carbon Disclosure Project (CDP) is a collaboration of around 400 institutional investors with a combined $\$ 57$ trillion of assets under management. On their behalf, CDP seeks information on the business risks and opportunities presented by climate change and greenhouse gas emissions data from the world's largest companies (ACCA, 2010). Sabanci University is the local partner of CDP in Turkey with the sponsorship of Akbank and report sponsorship of Ernst \& Young Turkey. The project was first launched in January 2010. In 2012, companies included in the Istanbul Stock Exchange 100 (ISE-100) index were invited to respond to CDP's information request. In addition, CDP Turkey accelerated its efforts to increase voluntary responses from Turkey's carbon-intense sectors. As a result, the number of voluntary respondents increased significantly from 2011. In 2012, 17 of the ISE-100 companies responded to the CDP questionnaire, and 32 Turkish companies in total responded to CDP including non-ISE-100 respondents (CDP, 2013).

Turkey is already a player in carbon finance and trading through the voluntary carbon market route and this activity is growing. In the period 2008-2012, participation in the Voluntary Carbon Markets (VCMs) has been the only market tool for Turkey. Approximately $218 \mathrm{VCM}$ projects were developed and/or implemented in Turkey in that period. Majority of these projects focus on renewable energy sources such as hydroelectricity, wind, and geothermal, yet there are also other projects focusing on industrial energy efficiency projects, power generation from waste and biomass (PMR, 2013). The first carbon transaction in Turkey is recently done by Bilgin Energy Holdings. In early June 2006, 3C and Bilgin Energy signed an Emission Reduction Purchase Agreement for 72,000 metric tonnes of emission reduction certificates from Turkey's first large scale wind power park located in the Balikesir (UNDP and EC, 2008).

\section{Literature Review}

The literature on the GHG disclosure is rich and deep. Papers have been published across a range of disciplines. Aquino (2009) determined the environmental disclosure practices of ten mining companies in the Philippines by examining the nature and extent of disclosures in the financial and non-financial sections of their 2006 corporate annual reports. It was found that there was no uniformity in the environmental disclosures of the ten mining companies. It was also discovered that there were no existing environmental reporting standards as far as environmental disclosure is concerned.

Owolabi (2009) investigated the degree of lessons learnt by companies in Nigeria with regards to their attitude towards the environment. The study examined annual report disclosures of environmental information of 20 companies from ten sectors (out of the 27 listed on the Nigerian Stock Exchange) that represent industries widely recognized to have environmental problems.

Gibson and O'Donovan (2007) reported on the quantity and categories of environmental information disclosed in the corporate annual reports of 41 Australian companies across eight industry groups covering the period 1983-2003. The results of this study indicated that an increasing number of companies were disclosing environmental information, and the relative volume of such information in annual reports was increasing across all categories.

Deegan and Gordon (1996) analysed the environmental disclosure practices of Australian corporate entities. They found that corporate disclosure practices in the period 1980 to 1991, environmental disclosure made by the sample significantly increases across time. This change is linked to an apparent increase in societal concern relating to environmental issues.

Stray (2008) selected two industrial sectors - the Water industry and the Energy industry - and the most recent Environmental Reports produced by companies in these sectors were subjected to content analysis where the coding framework was heavily based on the DEFRA guidelines. Whilst sectoral differences were 
found it was clear that many companies addressed most of the issues raised in the guidelines. However, others did not.

The paper of Ahsen, Lange and Pianowski (2004) presented an empirical study addressing current tendencies in corporate environmental reporting released to the public. They surveyed British and German environmental statements according to the EMAS. Empirical analysis revealed that British and NorthrhineWestfalian environmental statements according to EMAS contain comprehensive information and even show significant enhancements over the years.

Perez and Sanchez (2009) reviewed 31 reports published between 2001 and 2006 by four major mining companies. A set of 62 assessment items organized in six categories were selected to guide the review. A content analysis was performed using the report as a sampling unit, and using phrases, graphics, or tables containing certain information as data collection units. According to the findings, the biggest companies in the mining industry are clearly producing more comprehensive and more sophisticated sustainability reports. However, improvements in coverage of the sustainability agenda, accuracy of information, and the verification of the information provided are only part of the requirements.

Freedman and Jaggi (2005) evaluated disclosures on pollution and greenhouse gases by firms domiciled in countries that ratified the Kyoto Protocol compared to others. The study was based on disclosures made in the annual reports, environmental reports, and websites of 120 of the largest (in terms of revenues) public firms from the chemical, oil and gas, energy, and motor vehicles and casualty insurance industries. Content analysis was used to construct weighted and unweighted disclosure indices. The results showed that firms from countries that ratified the Protocol had higher disclosure indexes as compared to firms in other countries and larger firms disclosed more detailed pollution information.

Reports such as that complied by the Association of Chartered Certified Accountants (the ACCA), Henderson Global Investors and Trucost, Corporateregister, and the Carbon Disclosure Project show the extent to which companies are voluntarily disclosing the facts on climate change.

\section{Research Setting And Methodology}

The study is descriptive in nature and determines the extent of the climate change and carbon disclosure practices of publicly-listed companies in Turkey. The study examined the disclosures of listed companies in order to investigate the changes in the level of corporate climate change and carbon disclosure. The secondary data were taken from the annual reports posted on the web sites of the listed companies.

This longitudinal study involved the analysis of the annual reports of 27 publicly listed Turkish companies (out of 100 listed on the ISE as of December 31, 2008) for the 3-year period 2006-2008, from ten carbon-intensive industries. Climate change and carbon disclosure practices of companies in the iron and steel, energy, cement, oil and gas, pulp and paper, chemicals, glass, compost, dye, airline industries were analyzed. The distribution of the selected companies by sectors is shown in Table 1. Content analysis technique that focuses on the substance of what is disclosed, rather than counting the lines of disclosure, is used to measure changing levels of information provision.

Table 1. Distribution by Sectors

\begin{tabular}{lcc}
\multicolumn{4}{c}{ Table 1. Distribution by Sectors } \\
\hline Sectors & No. & \% \\
\hline Energy & 2 & 7 \\
Cement & 4 & 15 \\
Oil and Gas & 5 & 19 \\
Iron and Steel & 3 & 11 \\
Pulp and Paper & 2 & 7 \\
Airline & 2 & 7 \\
Glass & 3 & 11 \\
Chemicals & 2 & 7 \\
Dye & 1 & 4 \\
Compost & 3 & 11 \\
\hline Total & $\mathbf{2 7}$ & $\mathbf{1 0 0}$ \\
\hline
\end{tabular}

Content analysis of 81 annual reports was conducted. The data were grouped and analysed as a whole, and also on an industry basis, to enable comparison within and between industry groups. In order to review the selected annual reports, the following items were selected to frame the evaluation, partially based on the Climate Communications Report 2007. 
Whether or not:

-the reports address climate change.

-the reports include quantitative data on carbon emissions.

-the companies are taking measure to reduce their carbon emissions.

-the companies have certificate of emission standards.

-the companies obtained ISO 14001 certificate.

\section{Findings}

The study examined whether annual reports address climate change and whether they include quantitative data on carbon emissions. Suprisingly, there is only one company that included carbon performance information in its annual reports. Moreover, only seven companies mentioned climate change in their annual reports and mostly for only the last year of the study. Disclosures related to the remaining three items examined in the annual reports for each of the 27 companies are given in Table 2.

According to the findings, 13 companies have disclosures related to carbon emission abatement efforts in their annual reports. Of these 13 companies, 10 companies have these disclosures for all of the three years, one of them has for the years 2007 and 2008, and two of the companies have for only 2008.

Table 2. Disclosures

\begin{tabular}{|c|c|c|c|c|}
\hline Sectors & Firms & $\begin{array}{l}\text { Emission reduction } \\
\text { efforts }\end{array}$ & $\begin{array}{l}\text { Certificates of emission } \\
\text { standards }\end{array}$ & ISO 14001 certificates \\
\hline \multirow{2}{*}{ Energy } & AKENR & $* * *$ & - & -7 \\
\hline & ZOREN & $*$ & - & $* * *$ \\
\hline \multirow{4}{*}{ Cement } & ADANA & $* * *$ & $* * *$ & $* * *$ \\
\hline & AKCSN & $* * *$ & $* * *$ & $* * *$ \\
\hline & CIMSA & $* * *$ & - & $* * *$ \\
\hline & AFYON & - & - & -7 \\
\hline \multirow{5}{*}{ Oil and Gas } & PTOFS & $* * *$ & $* * *$ & $* * *$ \\
\hline & TUPRS & $* * *$ & $* *$ & $* * *$ \\
\hline & PETKM & $* * *$ & - & - \\
\hline & AYGAZ & - & - & $* * *$ \\
\hline & TRCAS & - & - & - \\
\hline \multirow{3}{*}{ Iron and Steel } & EREGL & $* * *$ & $* *$ & $* * *$ \\
\hline & IZMDC & - & - & $*$ \\
\hline & KRDMD & - & - & - \\
\hline \multirow{2}{*}{ Pulp and Paper } & KARTN & $* * *$ & - & $* * *$ \\
\hline & ISAMB & - & - & -1 \\
\hline \multirow{2}{*}{ Airline } & CLEBI & $* *$ & - & $* *$ \\
\hline & THYAO & $*$ & - & -1 \\
\hline \multirow{3}{*}{ Glass } & SISE & $* * *$ & - & $* * *$ \\
\hline & EGSER & - & - & - \\
\hline & TRKCM & - & - & - \\
\hline \multirow{2}{*}{ Chemicals } & AKSA & - & - & $* * *$ \\
\hline & ALKIM & - & - & - \\
\hline Dye & DYOBY & - & - & -1 \\
\hline \multirow{3}{*}{ Compost } & BAGFS & - & - & - \\
\hline & EGGUB & - & - & - \\
\hline & GUBRF & - & - & - \\
\hline
\end{tabular}

*** The first “*” denotes that related information is disclosed for 2008, second for 2007, and third for 2006.

- No disclosure is found out.

${ }_{-}^{+}$Efforts to fulfill the ISO 14001 requirements are going on. 


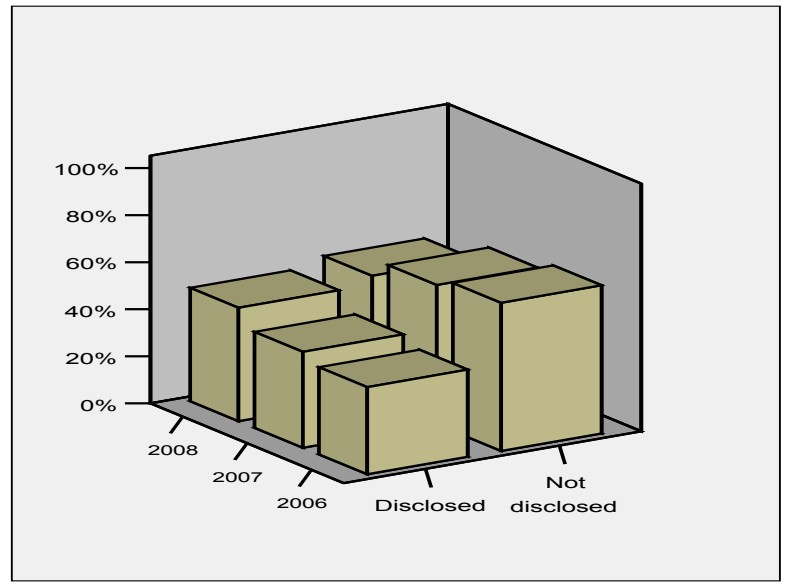

Figure 1. Abatement Efforts

As shown in Fig. 1, there is a slight increase in disclosures related to emission abatement efforts of the companies; while 10 companies disclosed in 2006, the number of the companies disclosed related information reached 13 in 2008. However, the percentage of these companies as of 2008 remained under $50 \%$.

According to the regulations in Turkey, a Certificate of Emission Standard (CES) is required if the company's emission exceeds a certain limit. As shown in Table 2, according to the annual reports, only 5 of the companies have CES. Of these 5 companies, three companies have this certificate for three years. The remaining two have their certificate for two years. The number of companies with CES has been slightly increasing. There seems to be a relation between having disclosures of CES and carbon abatement efforts. However, the number of companies willing to reduce their carbon emissions is more than the number of companies with certificate of emission standards. The reason of this difference may be explained as follows; although they have the certificate they do not disclose this information in their annual reports, or their carbon emission is under the limit, so they do not need to have the certificate. As Fig. 2 depicted below shows, the percentage of the companies with this certificate is around $20 \%$.

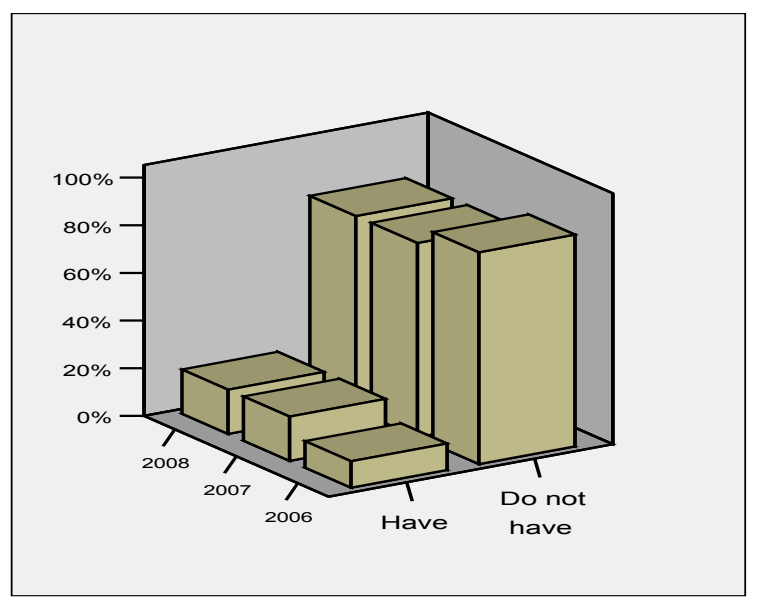

Figure 2. Certificate of Emission Standards

As shown in Table 2, 13 of the companies examined in this study have ISO 14001: Environmental Management Systems Certificate, whereas 5 companies have been pursuing to obtain ISO 14001 certificate. The findings show that there is a relationship between having ISO 14001 certificate and disclosures of carbon emission abatement efforts. Ten of the companies that have disclosures of carbon emission abatement efforts, have ISO 14001 certificates, as well. Besides, 2 of them have been started with the process to obtain ISO 14001 certificate.

As shown in Fig. 3, there is a slight increase in the percentage of companies with ISO 14001 certification; however, the percentage is still around $40 \%$.

When findings are considered with respect to the aforementioned sectors, it is clear that the companies in the energy, cement, oil and gas sectors disclose the related information more than the other sectors, especially 
compost and dye. Table 2 shows that the number of companies that have CES in cement and oil and gas sectors, is higher than the other sectors. The reason for this is the carbon-intensive character of these two sectors.

Three companies have all of the three disclosures for 2006, 2007 and 2008. Only two companies have all of the disclosures for 2007 and 2008.

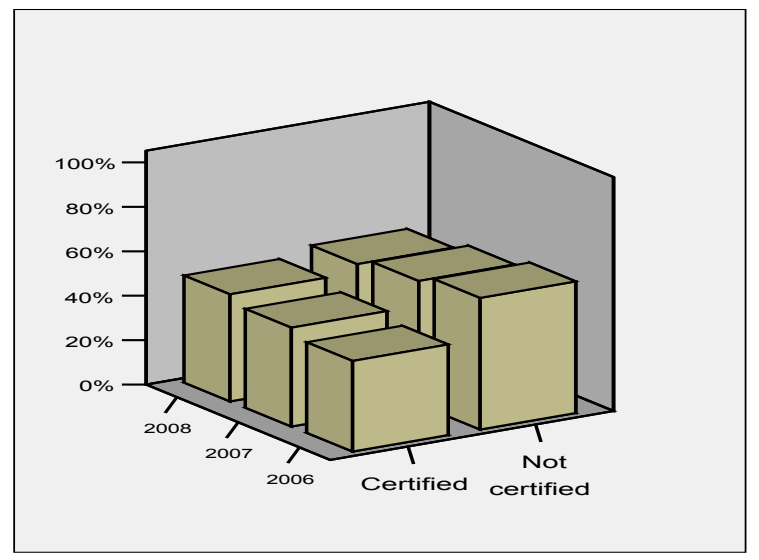

Figure 3. ISO 14001 Certification

\section{Conclusion}

This study has documented a review of corporate reporting on carbon emissions and climate change made by Turkish listed companies in their annual reports. The study sought to consider whether annual reports address climate change, include quantitative data on carbon emissions, and also whether the companies are taking measures to reduce their carbon emissions, have certificate of emission standards and have obtained ISO 14001 certificate. This study is among the first to examine the extent of disclosures related to carbon emission and climate change in Turkey.

Analysis of disclosures indicates that the disclosures of the selected companies are at a limited level. While almost $50 \%$ of the selected companies made disclosures related to carbon emission abatement efforts, there is only one company disclosing quantitative performance data on carbon emissions. Additionally, climate change and carbon disclosures of the selected companies are underdeveloped and information disclosed is brief, mostly descriptive, narrative in nature and varied in content and form.

Environmental information reporting and disclosure in annual reports in Turkey is still voluntary; this partly explains the low level of disclosure among Turkish companies. In order to improve carbon emission disclosures, lack of voluntarism may lead regulators to consider mandatory disclosure requirements. This paper conjectures that the increased focus on environmental issues and future regulations will lead disclosures to be more detailed and comparable.

This study covers the 3-year period before ratification; the disclosure level will continue to be studied for the years after the ratification of the Kyoto Protocol. Prospective studies may be conducted on the subject by making a regression analysis in order to determine which factors are affecting the disclosures mentioned in this study and if there is any relation between them.

\section{Acknowledgements}

This paper is a revised version of a paper originally presented at the $34^{\text {th }}$ Annual Congress of European Accounting Association (EAA), Italy, April, 2011. I should like to acknowledge the helpful comments of the participants.

\section{REFERENCES}

[1]. NSF (2011). Accessed: 5th May 2013, An introduction to the global carbon cycle. Available at: $<$ http://globecarboncycle.unh.edu/CarbonCycleBackground.pdf $>$

[2]. ACCA (2010). Accessed: 5th January 2010, Carbon Jigsaw Briefing: The Science of Climate Change., Available at: $<$ http://www.accaglobal.com/documents/tech_tp_cjb_science.pdf $>$

[3]. Bebbington, J., \& Larrinaga-Gonzalez, C. (2008). Carbon Trading: Accounting and Reporting Issues. European Accounting Review, 17(4), 697-717.

[4]. Porter, B.P., Simon, J., \& Hatherly, D. (2008). Principles of External Auditing. England : John Wiley\&Sons, Ltd.

[5]. Kaygusuz, K. (2009). Energy and environmental issues relating to greenhouse gas emissions for sustainable development in Turkey. Renewable and Sustainable Energy Reviews, 13, 253-270.

[6]. OECD. (2008). Eco-Innovation Policies in Turkey. Retrieved December 20, 2009, from http://www.oecd.org/dataoecd/28/34/42878896.pdf

[7]. Kaya, O. (2008). Companies Responses to Climate Change: The Case of Turkey. European Journal of Social Sciences, 7(2), 66-76. 
[8]. EEA (2007). Accessed: 12th April 2013, Greenhouse gas emission trends and projections in Europe 2007 - Country profile. Available at: $<$ http://www.eea.europa.eu/publications/eea_report_2007_5/Turkey.pdf $>$

[9]. MFA (2011). Accessed: 1st March 2013, United Nations Framework Convention on Climate Change (UNFCCC) and the Kyoto Protocol. Available at: <http://www.mfa.gov.tr/united-nations-framework-convention-on-climate-change-_unfccc_-and-the-kyotoprotocol.en.mfa>

[10]. UN (2013). Accessed: 23rd June 2013, Opportunities for Parties included in Annex I to the Convention whose special circumstances are recognized by the Conference of the Parties to benefit from support from relevant bodies and institutions to enhance mitigation, adaptation, technology, capacity-building and access to finance. Available at: $<$ http://unfccc.int $/$ resource/docs $/ 2013 / \mathrm{tp} / 03$.pdf $>$

[11]. UNFCC (2009). Accessed: 12th April 2013, Reporting Requirements, Available at: $<$ http://unfccc.int/national_reports/annex_i_ghg_inventories/reporting_requirements/items/2759.php $>$

[12]. UNDP and EC (2008). Accessed: 15th November 2010, Turkey Corporate Social Responsibility Baseline Report. Available at: $<$ http://www.undp.org.tr/publicationsDocuments/CSR_Report_en.pdf $>$

[13]. Aydin, C.A., Turker, Y.O., \& Velioglu, N. (2010). Air pollution regulations in Turkey and harmonization with the EU legislation. iForest, 4, 181-185.

[14]. CDP (2013). Accessed: 19th April 2013, CDP Turkey 100 Climate Change Report 2012. Available at: $<$ https://www.cdproject.net/CDPResults/CDP-Turkey-100-Climate-Change-Report-2012.pdf $>$

[15]. PMR (2013). Accessed: 11th June 2013, Market Readiness Proposal. Available at:< https://www.thepmr.org/system/files/documents/TUR-FINAL-MRP_2013-05-03\%20Final.pdf>

[16]. Aquino, N.M. (2009). An Evaluation of Financial and Non-Financial Environmental Disclosures of Ten Publicly-Listed Mining Companies in the Philippines. DLSU Business \&Economics Review, 18(2), 55-64.

[17]. Owolabi, A. (2009). Environmental Disclosures in Annual Reports: The Nigerian Perspective. Economia Aziendale Online, 1, 151160 .

[18]. Gibson, K., \& O’Donovan G. (2007). Corporate Governance and Environmental Reporting: an Australian Study. Corporate Governance, 15(5), 944-956.

[19]. Deegan, C., \& Gordon, B. (1996). A Study of the Environmental Disclosure Practices of Australian Corporations. Accounting and Business Research, 26(3), 187-199.

[20]. Stray, S. (2008). Environmental Reporting: The U.K. Water and Energy Industries: A Research Note. Journal of Business Ethics, 80, $697-710$.

[21]. Ahsen, A., Lange, C., \& Pianowski M. (2004). Corporate environmental reporting: survey and empirical evidence. International Journal of Environment and Sustainable Development, 3(1), 5-17.

[22]. Perez, F., \& Sanchez L.E. (2009). Assessing the Evolution of Sustainability Reporting in the Mining Sector. Environmental Management, 43, 949-961.

[23]. Freedman, M., \& Jaggi, B. (2005). Global warming, commitment to the Kyoto protocol, and accounting disclosures by the largest global public firms from polluting industries. The International Journal of Accounting, 40, 215-232. 